\title{
Educational Multimedia Materials in Academic Medical Training
}

\author{
Barbara Kołodziejczak ${ }^{1}$, Magdalena Roszak ${ }^{1}$, Wojciech Kowalewski², \\ Anna Ren-Kurc ${ }^{2}$ \\ 1 Department of Computer Science and Statistics, Poznan University of Medical Sciences, \\ Poland \\ 2 Faculty of Mathematics and Computer Science, Adam Mickiewicz University, Poznan, \\ Poland
}

\begin{abstract}
This article presents an overview of generally available applications for creating multimedia and interactive educational materials, such as presentations, instructional videos, self-tests and interactive repetitions. With the use of the presented tools, pilot materials were developed to support the teaching of biostatistics at a medical university. The authors conducted surveys among students of faculties of medicine in order to evaluate the materials used in terms of quality and usefulness. The article presents the analysis of the results obtained.
\end{abstract}

\section{Building Educational Materials}

It is every academic teacher's daily and time-consuming duty to prepare teaching materials for their subject. In order to improve the efficiency and quality of teaching university students, we now tend to use more electronic materials that make traditional presentation of the covered issues more attractive and enriched (Karmelita et al., 2012; Mokwa-Tarnowska, 2014). The use of multimedia resources in the teaching process is natural and desirable, while preparation of such resources must be relatively simple so that each university teacher is capable of doing it by themselves. Lack of time, inability to operate specialized software (Ren-Kurc et al., 2012), and lack of belief in the influence the format of presented contents has on teaching efficiency and quality - these are the most common reasons for not preparing electronic teaching aids.

Teaching materials, usually including lectures and practical classes, may include such elements as:

- text resources with graphic elements (charts, diagrams, figures), 
- interactive materials, such as educational games, simulations, decision labyrinths, tests, quizzes,

- multimedia resources: presentations, videos, animations, and sound recordings.

Building such electronic resources requires university teachers to have adequate ICT competence and to choose relevant IT tools. The choice of tools largely depends on the author's level of skill, the requirements concerning the materials themselves, e.g. their quality and contents, and available financial resources (e.g. purchase of licenses). The key issue seems to be the availability and user-friendliness of the applications. Other basic requirements for tools used in creating educational materials are (Kołodziejczak et al., 2013):

- easy building and later updating of contents,

- creating materials on the basis of readily available templates,

- ability to merge with existing contents, to insert graphic items and multimedia,

- ability to publish contents in formats consistent with applicable standards,

- ability to work on (read/write) multiple file formats,

- ability to merge educational content with various forms of student activity,

- ability to structure knowledge while maintaining attractive form,

- ability to add instructions, feedback and summaries for the learner,

- no need to use programming languages while creating the aids.

Despite the fact that the above set of requirements seems obvious, it does contain a certain inconsistency. Namely, on one hand we expect the applications to be simple and intuitive for the user, and on the other hand, we expect them to give the author an extensive range of advanced content building and student activity options. There are multiple tools available on the market, with more or less restrictive licenses (including freeware). Thus, finding software with specific desired functionality may be time-consuming and troublesome, particularly for beginners in the field of creating electronic educational materials.

\section{Suggested Tools}

The authors of the article suggest that the process of building multimedia teaching aids be commenced on the basis of known and tried tools, and that the user continues to expand the available options through merg- 
ing in other new applications. Such an approach shortens the time needed to learn how to operate completely new software, and reduces fear of failure, particularly for individuals with poor computer skills. In light of the above considerations, PowerPoint seems to be the obvious choice as the basic tool. Almost every teacher has prepared presentations for their classes in this environment and therefore has certain experience in using it, as well as ready-to-use teaching aids. Now what they need to do is to expand PowerPoint's options. The authors suggest that several selected tools be reviewed:

1. iSpring Free,

2. Windows Live Movie Maker,

3. CamStudio,

4. Articulate Rapid E-Learning Studio '09,

5. Learning Content Development System (LCDS),

6. LCDS Learning Snack.

The choice of tools presented is not accidental and relates to the ability to combine these tools into functional sets (Figure 1). The central point is a presentation created in PowerPoint, which may then be combined with other teaching aids and saved as videos or embedded objects on an HTML page, easily published in LMS (Learning Management System) portal resources.

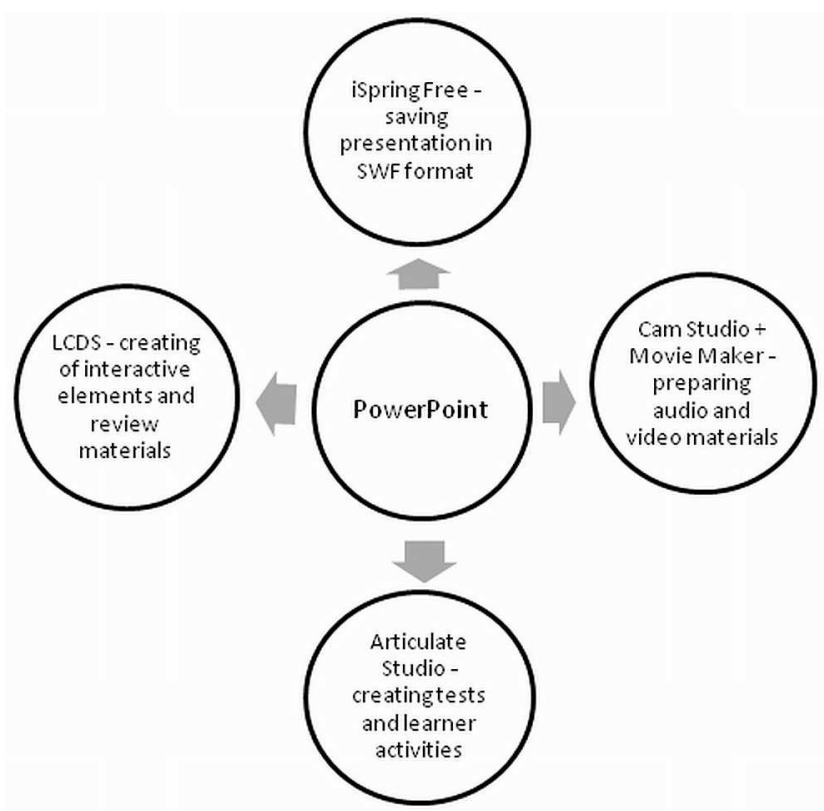

Figure 1. The combination of the programs in the set - a proposal of the authors 
Barbara Kotodziejczak et al.

Although these tools are not new on the market, they may provide great support to persons who are beginning to work on creating electronic versions of educational materials. Their advantage is the combination of maximum options with a simple and intuitive interface. Most of them are applications available on the basis of a freeware license, which may be important if you do not have a large budget.

\section{Microsoft PowerPoint 2010}

About $90 \%$ of all presentations are estimated to be produced in PowerPoint and, despite the competition of Flash technology programs, PowerPoint continues to be the leader among tools for creating educational materials at all levels of education (Kołodziejczak, 2011). Preparation of one hour of e-learning aids is estimated to take 73 to 220 hours, while conversion of a PowerPoint presentation into such materials takes 33 hours on average (Kapp et al., 2009). The advantages of this application include availability and user-friendliness. Another strong point of PowerPoint is the extensive range of available templates, motifs, and a rich set of graphic and animation effects. With hyperlinks, non-linear navigation can be provided in an educational presentation. In that case, the system of interlinks within the presented contents may have a complex hypertext structure where the learner chooses their own reading path. Active elements on slides may also link to instructions or hints. Another advantage of this application is the ability to embed and convert multimedia, as well as to handle such multimedia with little effort and without advanced programming skills. Therefore, PowerPoint meets a lot of requirements concerning tools for building educational contents. The primary disadvantage of this software is the lack of integrated mechanisms for creating tests, quizzes and interactive elements.

For copyright reasons, materials created in PowerPoint are usually published in PDF format with enabled protection against copying contents. This storage format flattens animations and videos from the presentation to $2 \mathrm{D}$ images and prevents attaching narration, which eliminates information that might be very important. As an alternative, a presentation can be saved in SWF (Adobe Flash) format.

\section{iSpring Free}

The free version of the iSpring application allows storage of PowerPoint presentations in SWF format. By storing presentations in this format, a complete animation will be automatically embedded on a website and you 
can view its contents in a Web browser (Figure 2). iSpring Free is fully integrated with PowerPoint and all options are available from the PowerPoint menu (Figure 3). An advantage of this application is that animations and active elements defined in the presentation are maintained, as well as multimedia materials, such as videos and soundtracks.

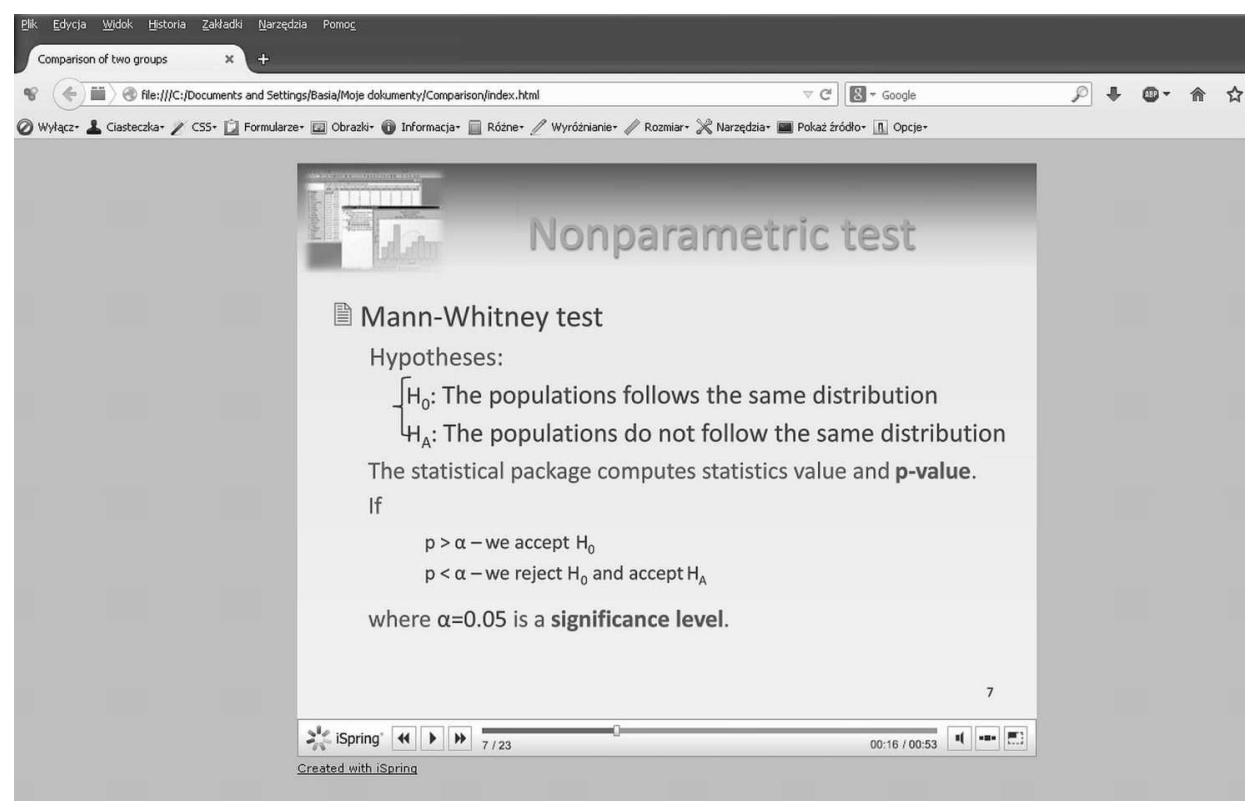

Figure 2. PowerPoint presentation saved as flash animation and viewed in the Mozilla Firefox browser - biostatistics material for medical students

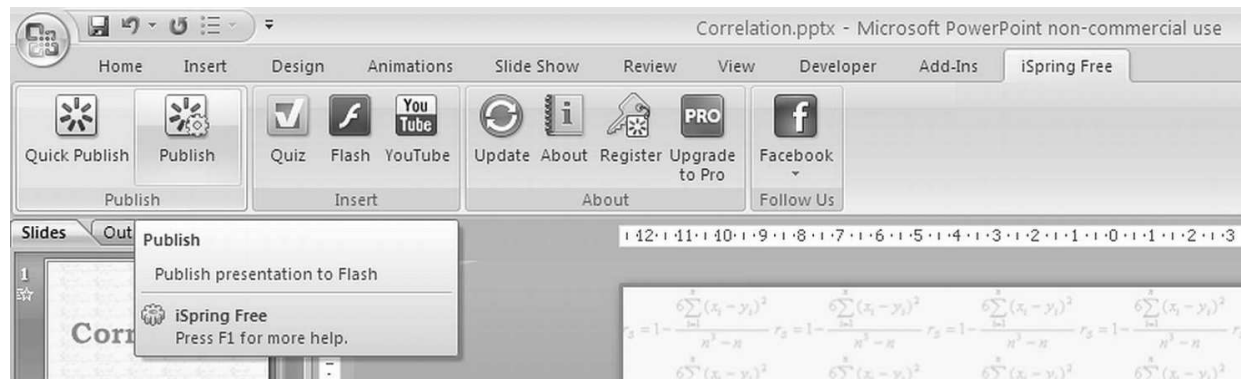

Figure 3. iSpring Free options available on the PowerPoint ribbon

For those interested in expanding PowerPoint options for user interaction through quizzes, questionnaires and various types of student activities, the authors recommend Articulate Rapid E-Learning Studio. 
Barbara Kotodziejczak et al.

\section{Articulate Rapid E-Learning Studio '09}

Articulate Rapid E-Learning Studio '09 is a package of applications for creating e-learning materials based on PowerPoint. The package consists of 4 applications: Articulate Quizmaker, Articulate Engage, Articulate Presenter and Video Encoder. Each tool is a separate program. In addition, when you install Articulate Studio, an additional Articulate tab will be shown on the PowerPoint ribbon. The commands available there extend the PowerPoint options with Articulate Studio functions, such as recording narration for slides, inserting notes, synchronization of animation with narration, editing audio files, and adding quizzes, Flash items or Learning Games (Shank et al., 2009).

In terms of creating educational materials, the most important applications are Articulate Quizmaker and Engage.

With Articulate Quizmaker, you can create graded or non-graded tests (questionnaires). The application allows you to:

- group questions by topic,

- define a random order and number of questions in each topical group,

- branch a test according to the answer given to a previous question,

- add a time limit for completing the test.

Feedback regarding whether the given answer was correct or incorrect may be provided for every question on a test or questionnaire. Quiz results are presented as a summary and the student may review his or her answers accordingly (Figure 4).

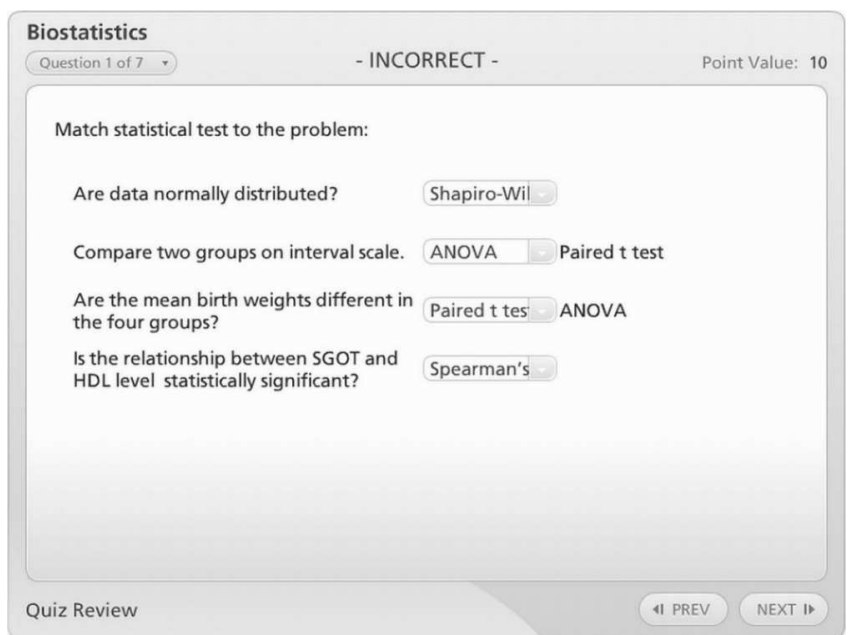

Figure 4. Quiz review with feedback comments - biostatistics material for medical students 
The application allows you to print the results or e-mail them to the teacher. If the materials are embedded on an LMS portal or Articulate Online, results are incorporated in course scores through a mechanism available on the portal.

Articulate Quizmaker offers various types of test questions, starting with single and multiple choice tests, true/false questions, matching answers (Matching Drag and Drop, Word Bank), and ordering answers into the right sequence (Sequence Drag and Drop), to tests with computation questions and with active elements (Hot Spot). A total of 11 interface types for building test questions are available.

Questions for questionnaires are created on the basis of 9 available templates, such as: Likert scale questions, choice of one or multiple options, entering a brief answer or essay, ordering statements into a sequence, giving an answer in the form of a number.

Due to the use of templates, Articulate Engage allows you to create interactive presentations in several minutes. Ten different forms of student activity are available, including:

- FAQ - a set of active links to answers of frequently asked questions,

- Process - activities that define stages or phases of a linear procedure or process,

- Tabs - a task to define a set of elements which are somehow connected, such as a sequence of concepts, group members, or differences between objects (Figure 5),

- Timeline - a tool to help students visualize events in chronological order on a timeline,

- Glossary - an alphabetically ordered list of active links to terms in a dictionary.

Articulate Studio'09 is a commercial software product. With an EDU license, purchasing costs can be reduced. Its popularity stems from a combination of extensive content building options and a simple interface and easy publication process, whether in local resources or in LMS portal resources.

Video tutorials have a special position among today's educational materials. A video message has a significantly stronger impact on learners than a verbal description, while, for example, a presentation of an application in action allows you to quickly learn about its properties. There are a lot of examples available on YouTube and thematic portals (e.g. http://medtube.pl/). All you need to create such materials is an application for recording video from a computer screen, and a simple video editor. The authors suggest trying CamStudio and Windows Live Movie Maker. 
Barbara Kotodziejczak et al.

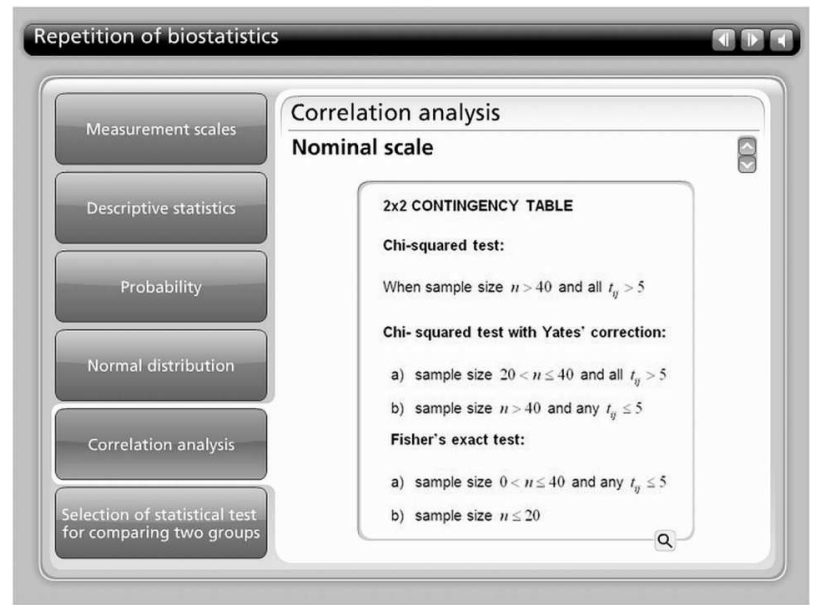

Figure 5. Repetition of biostatistics material using the Tabs interaction

\section{CamStudio}

CamStudio is a freeware tool for recording video sequences from a computer screen, mainly for the purpose of creating instructional videos. Together with video sequences, you can also record sound from the microphone or speakers, such as a commentary to the demonstrated activities. The program records all user operations, such as: movements with mouse cursors, launching applications, entering text, etc. Text comments can be added during video recording in ready-to-use shapes (clouds, arrows, balloons, etc.). In addition, you can use this application to convert AVI files generated by default into flash animations (Figure 6). Recorded footage usually needs to be processed further in a video editor.

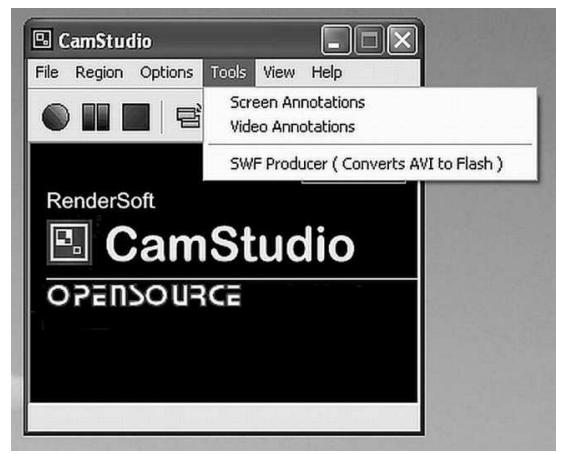

Figure 6. CamStudio allows users to convert AVI files into flash animations 


\section{Windows Live Movie Maker}

Microsoft Windows Live Movie Maker is a free, simple and efficient video editor. In Windows XP, Movie Maker is installed automatically with Service Pack 2 (SP2). In Windows 7 and Windows 8, Live Movie Maker is a part of the Windows Essentials 2012 package.

You can load source video footage from a file or capture it directly from an external source (such as a digicam, TV tuner). While processing video footage, you can add illustrations in the form of graphic images or video frames, special effects, subtitles, background music and narration (Figure 7). Then, you can share your videos on the Web, e-mail them or save them on CDs (Wimmer, 2010). The main disadvantage of this application is the limitation of video footage export options to one available format WMV or MP4, depending on the version.

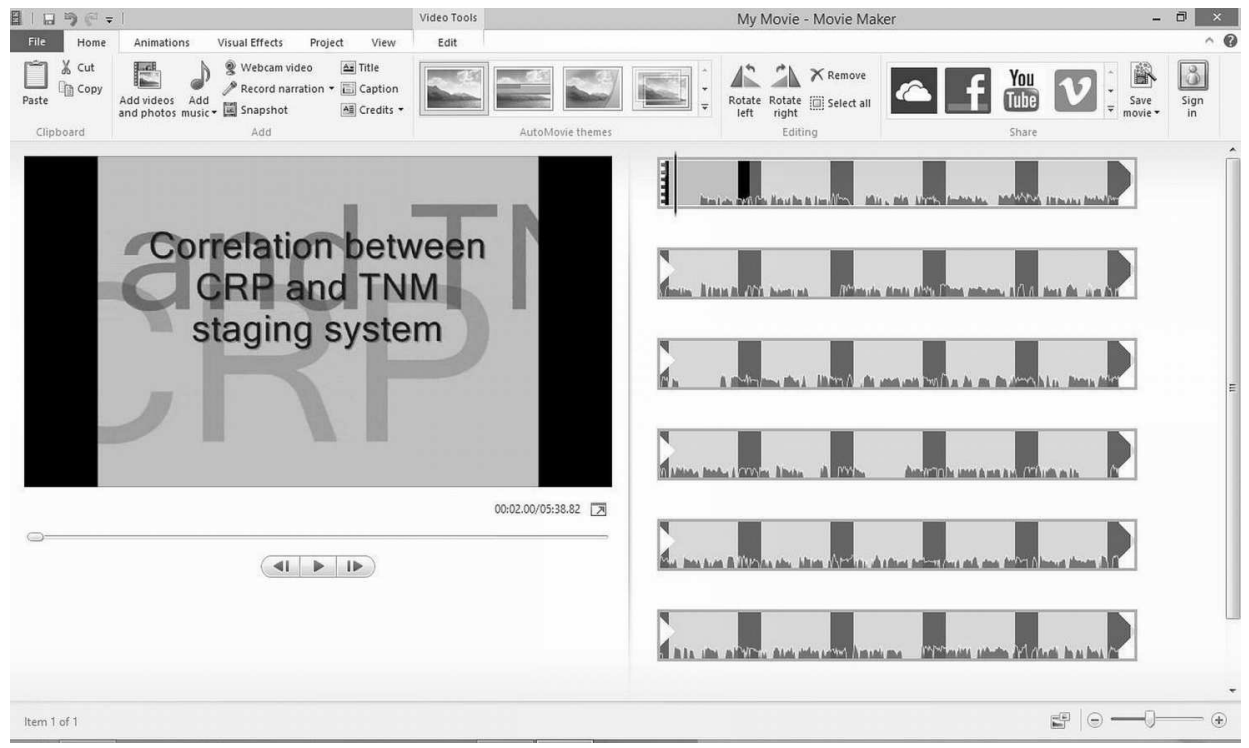

Figure 7. Editing of video materials for the subject of biostatistics in Windows Live Movie Maker

CamStudio with Windows Live Movie Maker can be used as an alternative to the commercial Camtasia Studio software. Interactive elements constitute an important portion of educational materials, with a significant impact on the processes of memorization (Roszak et al., 2013a). The growth of programming technologies has broadened the range of available interactive technologies with such options as games, simulations, or decision labyrinths, 
Barbara Kotodziejczak et al.

which are adapted to the unique features of presented knowledge. PowerPoint has no integrated mechanisms for creating interactive elements. The authors suggest that these be created in LCDS (Learning Content Development System) - an editor for creating interactive educational materials and repetitions. Its features are described in an article by Roszak et al. (2013b). As a reminder, there is some basic information about this program below.

\section{Learning Content Development System and LCDS Learning Snack}

Microsoft Learning Content Development System is a freeware tool for building advanced interactive educational materials. The entire product works with Silverlight technology and comprises 24 templates for building educational contents, including 6 available with repetitions. Templates allow for simple generation of diversified contents, from full course materials with animations and demonstrations, to various forms of student activities, tests, quizzes, and educational games (Figure 8).

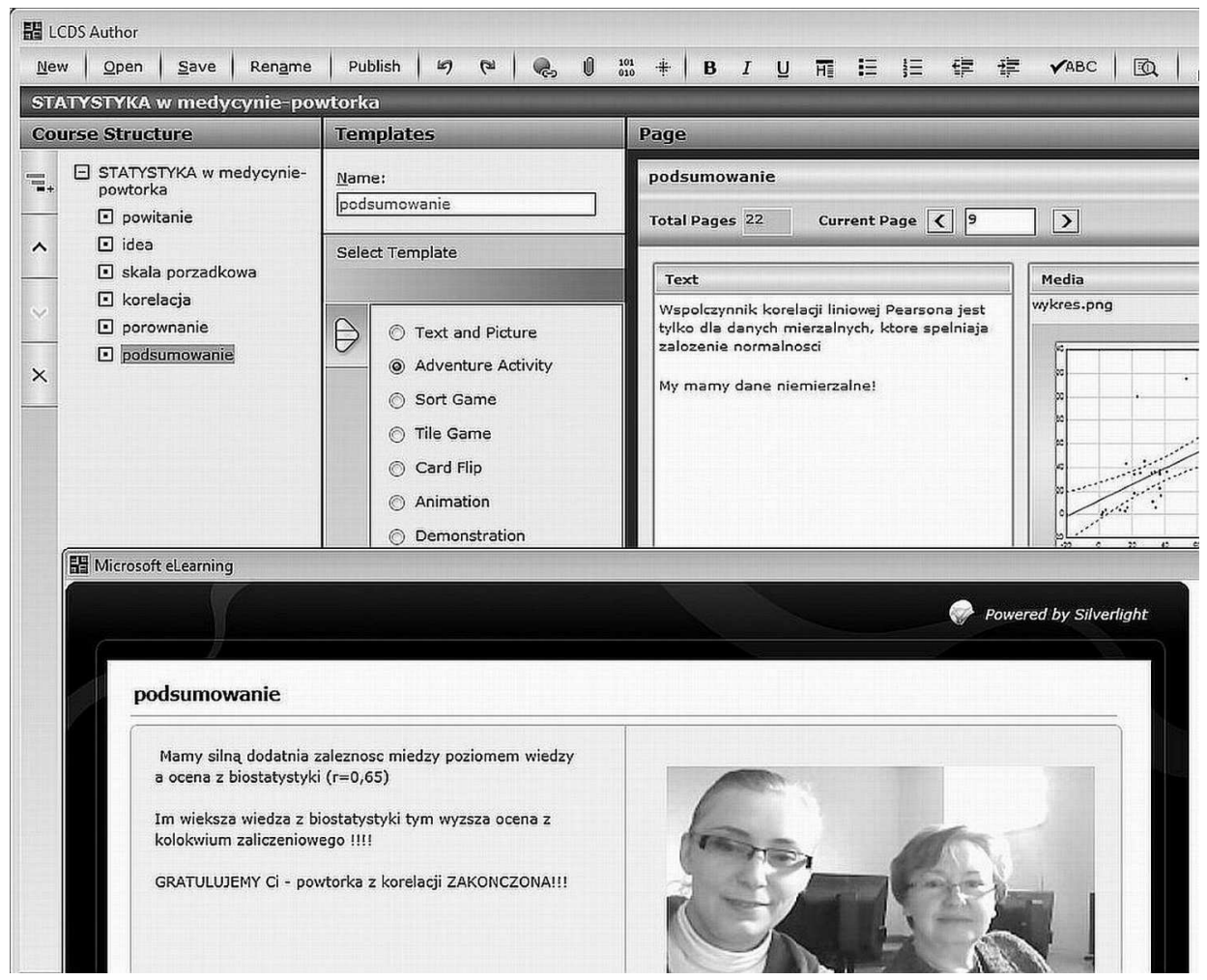

Figure 8. Creating an Adventure Activity in LCDS for Polish medical students 
LCDS Learning Snack is a free add-on to LCDS that can be used for quick preparation of refresher materials. These are created on the basis of finished learning materials previously edited in LCDS (through selecting key notes for the course), or in a typical way for the given batch of material, as complementary examination resources. Another option is the export of contents to an RTF file.

\section{Example Pilot Application}

The tools discussed above were used by the authors to create educational materials for the subject of biostatistics, which were then implemented into course classes in this subject. The classes were attended by 24 students of the $4^{\text {th }}$ year of medicine (two groups of students) taking a full-time course at the Medical University in Poznań during the 2011/2012 academic year.

The materials included a theoretical part (presentations) and a practical part, i.e. step analysis of a research problem in two statistical packages: STATISTICA by StatSoft and InStat by GraphPad. All was supplemented with video footage including verbal comments, as well as interactive repetitions and self-tests. The materials were planned and prepared so that they could be used either as a supporting element for traditional classes in a computer room or for independent work by the student, e.g. as a repetition before a test.

After the end of the course, the authors carried out an evaluation of the quality and usefulness of the implemented multimedia materials. The electronic questionnaire contained closed-ended and open-ended questions concerning the structure of the materials themselves and the form of class taught with the use of these materials. The students who took part in the survey had had no prior experience with remote classes or learning with the use of multimedia learning materials.

Survey results were statistically analyzed using relevant two-tailed tests: Chi-square with Yates correction, exact Fisher test, or FisherFreeman-Halton test. Spearman's rank correlation analysis was used as well. Calculations were carried out at a statistical significance of $\alpha=0.05$ in STATISTICA v. 10.0 from StatSoft and StatXact v.8.0 from Cytel Studio. 
Barbara Kotodziejczak et al.

\section{Results}

All students ( $n=24,100 \%)$ requested that academic teachers use multimedia materials (presentations with narration, videos, animations, interactive elements) more frequently throughout the teaching process. Seventy-one percent (17 out of 24) of survey participants indicated multimedia format in response to a question about their preferred format of presented learning contents, while $21 \%$ ( 5 out of 24 ) of participants chose the traditional format (chalk and blackboard), and $8 \%$ (2 out of 24 ) of participants replied "no preference". Then, the tested materials were evaluated in terms of method of content presentation and usefulness during the course of study (Table 1).

Table 1. Distribution of students' answers to survey questions about the quality and usefulness of the materials

\begin{tabular}{|c|c|c|c|c|c|}
\hline \multirow{2}{*}{ Question } & \multicolumn{5}{|c|}{ Answers } \\
\hline & $\begin{array}{c}\text { yes, } \\
\text { definitely }\end{array}$ & $\begin{array}{l}\text { yes, } \\
\text { quite }\end{array}$ & $\begin{array}{c}\text { cannot } \\
\text { say }\end{array}$ & no & $\begin{array}{c}\text { strongly } \\
\text { no }\end{array}$ \\
\hline $\begin{array}{l}\text { Did you consider the method } \\
\text { of content presentation in the } \\
\text { materials legible? }\end{array}$ & $\begin{array}{c}66.7 \% \\
16 \text { out of } 24\end{array}$ & $\begin{array}{c}33.3 \% \\
8 \text { out of } 24\end{array}$ & $0 \%$ & $0 \%$ & $0 \%$ \\
\hline $\begin{array}{l}\text { Did the video footage allow } \\
\text { you to better understand the } \\
\text { presented contents? }\end{array}$ & $\begin{array}{c}62.5 \% \\
15 \text { out of } 24\end{array}$ & $\begin{array}{c}37.5 \% \\
9 \text { out of } 24\end{array}$ & $0 \%$ & $0 \%$ & $0 \%$ \\
\hline $\begin{array}{l}\text { Would the materials be suffi- } \\
\text { cient for good understanding } \\
\text { of the topic if this was your } \\
\text { first encounter with this topi- } \\
\text { cal area? }\end{array}$ & $\begin{array}{c}25 \% \\
6 \text { out of } 24\end{array}$ & $\begin{array}{c}45.8 \% \\
11 \text { out of } 24\end{array}$ & $\begin{array}{c}25 \% \\
6 \text { out of } 24\end{array}$ & $\left|\begin{array}{c}4.2 \% \\
1 \text { out of } 24\end{array}\right|$ & $0 \%$ \\
\hline $\begin{array}{l}\text { Would it be a good idea to in- } \\
\text { corporate the tested learning } \\
\text { materials into traditional bio- } \\
\text { statistics classes? }\end{array}$ & $\begin{array}{c}58.3 \% \\
14 \text { out of } 24\end{array}$ & $\begin{array}{c}33.3 \% \\
8 \text { out of } 24\end{array}$ & $\begin{array}{c}8.3 \% \\
2 \text { out of } 24\end{array}$ & $0 \%$ & $0 \%$ \\
\hline
\end{tabular}

The use of multimedia materials was also reviewed in terms of incorporation into the learning process at several selected stages, such as: as a refresher before passing a subject, as a summary of material after covering the given topic, during class, other. The survey results indicate that the students' attitude is positive and that students can perceive the need to integrate electronic learning materials into medical education (Table 2). 
Table 2. Distribution of answers to the multiple-choice question "To which goal would you like to use multimedia materials (videos, interactive presentations, animations)?"

\begin{tabular}{|l|c|c|}
\hline \multicolumn{1}{|c|}{ Answer } & Percentage & $\begin{array}{c}\text { Number of } \\
\text { respondents }\end{array}$ \\
\hline refresher before course exam & $54 \%$ & 13 \\
\hline summary of material after the given topical area & $46 \%$ & 11 \\
\hline $\begin{array}{l}\text { during class, as a supporting element, a supplement } \\
\text { to course content }\end{array}$ & $29 \%$ & 7 \\
\hline introduction to a new topic (before class, entry or seminar) & $8 \%$ & 2 \\
\hline only during remote classes & $8 \%$ & 2 \\
\hline other & $8 \%$ & 2 \\
\hline
\end{tabular}

Four variants of biostatistics classes were proposed to the surveyed group of students, involving educational multimedia materials, and the students were asked to express their preference in this respect. Answers to this question are presented in Table 3.

Table 3. Distribution of answers to the question "Which form of biostatistics classes would you prefer?"

\begin{tabular}{|l|l|c|c|}
\hline Categories & \multicolumn{1}{|c|}{ Implementation } & Percentage & $\begin{array}{c}\text { Number of } \\
\text { respondents }\end{array}$ \\
\hline Traditional & $100 \%$ in-house classes & $0 \%$ & 0 \\
\hline Blended & $60 \%$ in-house classes, $40 \%$ online classes & $63 \%$ & 15 \\
\hline Alternating & $\begin{array}{l}50 \% \text { in-house classes, } 50 \% \text { online classes, } \\
\text { one local meeting and one online classes } \\
\text { following in alternation }\end{array}$ & $29 \%$ & 7 \\
\hline E-learning & $100 \%$ online classes & $8 \%$ & 2 \\
\hline
\end{tabular}

The surveyed students would rather vote for blended learning than for e-learning only, which only confirms the unique features of medical training.

The authors attempted to demonstrate the relationship between the studied issues and the observations taken during the class further. An analysis of the survey results confirmed that the content presentation method affects students' convictions about the need to integrate multimedia materials into traditional class structure $(p=0.026 ; r=0.45)$. Video footage allowed students to better understand the contents they were taught (Table 1) and had an effect on their willingness to integrate such elements 
into traditional classes $(p=0.025 ; r=0.46)$. On the other hand, evaluation of content presentation methods concerning educational materials bears no relation to evaluation of usefulness of the video materials introduced ( $p=0.212)$. According to the authors, students do not perceive the materials proposed to them as a single coherent educational whole but they evaluate each element separately. In addition, there is no relation between the evaluation of substantive content and usefulness of video materials and the opinion of whether the contents of the materials would be sufficient for proper understanding of the issue had the student encountered them for the first time $(p=0.08 ; p=0.79)$. No relation was proven $(p=0.612)$ between the forms of presented learning contents that were preferred by the students and the declared best form of biostatistics classes.

The students replied as follows as in Table 4 to the question "Why do you think teachers rarely use videos/presentations/interactive materials/animations in class?"

Table 4. Distribution of students' answers to the open-ended question "Why do you think teachers rarely use videos/presentations/ interactive materials/animations in class?"

\begin{tabular}{|l|c|c|}
\hline \multicolumn{1}{|c|}{ Students' answers - in descending order } & Percentage & $\begin{array}{c}\text { Number of } \\
\text { respondents }\end{array}$ \\
\hline lack of time & $38 \%$ & 9 \\
\hline lack of skill & $33 \%$ & 8 \\
\hline unwillingness & $29 \%$ & 7 \\
\hline too much time they would have to devote outside class & $25 \%$ & 6 \\
\hline attachment to traditional methods & $17 \%$ & 4 \\
\hline lack of technical facilities & $8 \%$ & 2 \\
\hline lack of payment & $8 \%$ & 2 \\
\hline fear of new technology & $4 \%$ & 1 \\
\hline because this may only be a supplement to class & $4 \%$ & 1 \\
\hline live explanation is quicker & $4 \%$ & 1 \\
\hline not everything can be shown in such materials & $4 \%$ & 1 \\
\hline lack of ideas for producing them & $4 \%$ & 1 \\
\hline
\end{tabular}

The following answers presented in Table 5, on the other hand, were given to the question "What would you change in the form/content of the presented issues to facilitate understanding of the topic more? What should be changed/added to the materials?" 
Table 5. Distribution of students' answers to the open-ended question "What would you change in the form/content of the presented issues to facilitate understanding of the topic more? What should be changed/added to the materials?"

\begin{tabular}{|l|c|}
\hline \multicolumn{1}{|c|}{ Students' answers - in descending order } & $\begin{array}{c}\text { Number of } \\
\text { respondents }\end{array}$ \\
\hline availability of materials outside class at any time & 3 \\
\hline the instructor may speak a bit faster & 2 \\
\hline add background music & 2 \\
\hline $\begin{array}{l}\text { after a few years when we need this knowledge these multimedia materials } \\
\text { (videos, verbal comments) would be great as a repetition }\end{array}$ & 1 \\
\hline more examples to study & 1 \\
\hline $\begin{array}{l}\text { only after finishing the given element can the learner follow with the next } \\
\text { portion of the issue }\end{array}$ & 1 \\
\hline $\begin{array}{l}\text { add more active elements such as hyperlinks (short definition) with terms } \\
\text { used as catchphrases - apparently not requiring explanation }\end{array}$ & 1 \\
\hline use less complicated language when explaining concepts & 1 \\
\hline add more extensive theoretical introduction and more interactive repetition & 1 \\
\hline soft manly voice & 1 \\
\hline show realization more slowly on videos & 1 \\
\hline $\begin{array}{l}\text { I really enjoyed it when the lady made a mistake on the video presenting } \\
\text { the example, which was not cut off but commented on }\end{array}$ & 1 \\
\hline I wouldn't change anything & 6 \\
\hline
\end{tabular}

The answers students usually gave to the open-ended question "What do you miss in medicine education in terms of usage of computers/Internet/ multimedia/new technologies?" were as follows: interactive presentations (9 respondents), electronic repetition tests (8 respondents) and videos presenting the given topic step-by-step (6 respondents).

It should be added that students had no technical problems while using the electronic materials. They enjoyed the idea of integrating a new form of class into the traditional biostatistics course and they asked for the ability to use the materials at home.

According to research results (Półjanowicz et al., 2010, 2013) and the authors' observations, positive learning motivation based on acceptance of the form and content of their study improves students' concentration on the issues taught, allows students to acquire knowledge faster, and improves teaching results. 
Barbara Kołodziejczak et al.

\section{Discussion}

The presented results of the pilot research study corroborate students' acceptance of new multimedia forms of learning materials. For the authors, this is an indication for further research in this direction and a confirmation of the right choice of tools and technologies used. The students' comments regarding what should be changed in the format and content of presented topics to improve them constitute a source of valuable information on what should be taken into account when preparing multimedia scenarios and creating the materials as such.

Medicine students would welcome multimedia learning materials in their classes and they highly value their usefulness in the learning process. They can see extensive options for implementing them in teaching medical subjects and they seek such materials on the Internet.

In the opinion of the students, there are still too few multimedia or interactive learning materials, which have a good effect on memory processes. Video materials with verbal comments or animations can significantly improve the quality and efficiency of learning, as their impact is much stronger than that of ordinary text and figures, which are still the default visual aids in teaching medical subjects. The students believe the main reasons for this situation are mainly lack of time and skills among teachers, as well as their attachment to traditional teaching methods (Table 4). Therefore, the authors claim that it is reasonable to promote examples of good practices and to point to easy-to-use tools for comprehensive preparation of materials, even for individuals with poor IT skills.

\section{Conclusion}

The research discussed in the article is an example of implementation of learning methods based on multimedia materials in the process of teaching biostatistics. These point to directions of further action to support the teaching of biostatistics and other subjects at a medical university.

Positive evaluation of the multimedia materials by students, along with their positive attitude and the fact that many of them even stated that they were waiting for more such initiatives, show teachers that it is reasonable to make the process of teaching medical subjects more advanced and attractive.

The overview of simple and generally available applications that is presented in this article may facilitate the choice of tools for building multimedia teaching materials for academic teachers, particularly outside IT-related 
faculties. The authors recommend that universities' websites publish comments about the applications that would best meet their expectations. Such recommendations should include data about access, as well as the installation process and available tutorials. Such a small service would allow staff members to determine the level of their ICT competence and to decide to take part in training in and outside the university. A lot of foreign schools' websites publish such regular information.

\section{R E F E R E N C E S}

Kapp, K. M., \& Defelice, R. A. (2009). Time to Develop One Hour of Training. Retrieved from Association for Talent Development website: http://www.astd. org/Publications/Newsletters/Learning-Circuits/Learning-Circuits-Archives /2009/08/Time-to-Develop-One-Hour-of-Training.

Karmelita, M., Rypina Ł., \& Królikowski, T., (2012). Interaktywne wspomaganie nauczania. Wirtualna Fizyka - innowacyjne rozwiązanie w edukacji. Ementor, 1(43), 53-56.

Kołodziejczak, B. (2011). Zastosowanie programu PowerPoint w e-learningu. Ementor, 5(42), 51-55.

Kołodziejczak, B., Roszak, M., Kowalewski, W., \& Ren-Kurc, A. (2013). Evaluation of the students knowledge with using rapid e-learning tools. In E. SmyrnovaTrybulska (Ed.), E-learning \& Lifelong Learning (pp. 189-201). Katowice: Studio Noa.

Mokwa-Tarnowska, I. (2014). Struktury wsparcia a efektywność kształcenia w środowisku e-learningowym. E-mentor, 2(54), 34-39.

Półjanowicz, W., Latosiewicz, R., Kulesza-Brończyk, B., Piekut, K., Kalisz, A., Piechocka, D. I., \& Terlikowski, S. J. (2010). Comparative analysis of elearning and traditional teaching methods in the field of nursing in the Medical University of Bialystok. In M. Banaszkiewicz, B. Kiełbratowska, \& M. Gierszewska (Eds.), The chosen aspects of woman and family's health (2, pp. 94-104). Bydgoszcz, Poland: Studio Reklamy i Poligrafii FOTOMAN.

Półjanowicz, W., Mrugacz, G., Szumiński, M., Latosiewicz, R., BakunowiczŁazarczyk, A., Bryl, A., \& Mrugacz, M. (2013). Assessment of the Effectiveness of Medical Education on the Moodle e-Learning Platform. Studies in Logic, Grammar and Rhetoric. Logical, Statistical and Computer Methods in Medicine, 35(48), 203-214.

Ren-Kurc, A., Kowalewski, W., Roszak, M., \& Kołodziejczak, B. (2012). Building Digital Content for E-Learning. Information and Communication Technologies (ICT) Competence. In E. Smyrnova-Trybulska (Ed.), E-learning for Societal Needs (pp. 201-212). Katowice-Cieszyn: Studio Noa. 
Barbara Kotodziejczak et al.

Roszak, M., Kołodziejczak, B., Ren-Kurc, A., \& Kowalewski, W. (2013a). Designing and building of interactive content for distance education. In E. SmyrnovaTrybulska (Ed.), E-learning \& Lifelong Learning (pp. 343-359). KatowiceCieszyn: Studio Noa.

Roszak, M., Kołodziejczak, B., Ren-Kurc, A., Kowalewski, W., \& Bręborowicz, A. (2013b). Learning Content Development System (LCDS) jako narzędzie tworzenia materiałów powtórkowych. E-mentor, 1(48), 40-46.

Shank, P., \& Bircher, J. (2009). Essential Articulate Studio '09. Sudbury: Wordware Publishing, Inc.

Wimmer, P. (2010). Domowy filmowiec. Windows Live Movie Maker 2011. Warszawa: Self Publishing. 